\title{
PubliCIDADE E AS MASCOTES DE MARCAS NO MERCADO PARAENSE
}

\author{
PubliCITY and the mascots of brands in the markets of \\ the state of Pará
PubliCIUDAD y las mascotas de marcas en el mercado de Pará

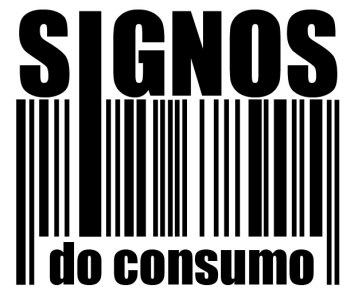

artigo

\author{
Luiz Cezar Santos \\ Universidade Federal do Pará, Belém, Brasil. \\ Graduado em Comunicação Social, com habilitação em Publicidade e Propaganda, pela Universidade \\ Federal do Pará (UFPA). Mestre em Estudos Literários pela Universidade Federal de Minas Gerais \\ (UFMG). Doutor em História pela Pontifícia Universidade Católica de São Paulo (PUC-SP). Pós-Doutor \\ em Comunicação e Consumo pelo Programa de Pós-Graduação em Ciências da Comunicação na \\ Escola de Comunicação e Artes da Universidade de São Paulo (PPGCOM/ECA-USP). Docente do \\ curso de Publicidade e Propaganda - Facom/ILC/UFPA e do Programa de Pós-Graduação em \\ Comunicação, Cultura e Amazônia (PPGCom/ILC/UFPA). Diretor Norte da Associação Brasileira de \\ Pesquisadores em Publicidade (ABP2). \\ E-mail: Izcezarpp@gmail.com
}

RESUMO $O$ artigo tem por premissa apresentar as pesquisas realizadas sobre as mascotes, personagens e personalidades do imaginário amazônico utilizadas no mercado paraense, para a construção e a sustentação de marcas. O estudo e a análise das peças publicitárias têm como foco o registro histórico das representações imagéticas das mascotes utilizadas pelas empresas comerciais na cidade de Belém do Pará, além de estudá-las como forma de publicização de marcas, produtos e serviços locais e regionais. A pesquisa revelou que as mascotes de marcas da região são prioritariamente compostas por animais domésticos e outros de baixo ou nenhum envolvimento cotidiano, o que evidencia o distanciamento da vasta fauna e do imaginário amazônico. Quando surgem as mascotes imaginativas, também as referências são distantes, como a utilização de mitos romanos ou de figuras universais, como o gênio. O maior vínculo de sentido local está na representação plural e extensiva da Nossa Senhora de Nazaré como personagem, portanto, mascote das festividades do Círio. O referido artigo, a partir do projeto de pesquisa intitulado publiCIDADE(s), analisa a propaganda e a publicidade como marca(s) midiática(s) de consumo, o projeto resultou ainda na apresentação e publicação de quatro trabalhos em anais de eventos nacionais da área.

PALAVRAS-CHAVE Mascotes, Personagens, PubliCIDADE, Consumo, Belém, Marca.

ABSTRACT The article aims to present the researches performed on the mascots, characters and personalities of the Amazonian imaginary used in the market of the state of Pará, for the construction and maintenance of brands. The study and analysis of the advertisements are focused on the historical record of the representations of the mascots used by commercial companies in the city of Belém do Pará, as well as studying them as a way of publicizing local and regional brands, products and services. The research revealed that the mascots of brands of the region are primarily composed by pets and others of low or no daily involvement, which shows the distancing of the vast fauna and the Amazonian imaginary. When imaginative mascots arise, references are also distant, such as the use of Roman myths or universal figures, like genius. The greatest bond of local meaning is in the plural and extensive representation of Our 
Lady of Nazareth as a character, therefore, mascot of the festivities of the Círio. This article, based on the research project titled publiCITY(ies) analyzes propaganda and advertising as a media brand(s) of consumption, also resulted in the presentation and publishing of four papers in proceedings of national events in the area.

KEYWORDS Mascots, Characters, PubliCITY, Consumption, Belém, Brand.

RESUMEN El artículo tiene por premisa presentar las investigaciones realizadas sobre las mascotas, los personajes y las personalidades del imaginario amazónico utilizadas en el mercado de Pará (Brasil), en la construcción y la sustentación de marcas. El estudio y el análisis de las piezas publicitarias se centran en el registro histórico de las representaciones imaginarias de las mascotas utilizadas por las empresas comerciales en la ciudad de Belém do Pará, además de estudiarlas como forma de publicidad de marcas, productos y servicios locales y regionales. La investigación reveló que las mascotas de marcas de la región se componen principalmente de animales domésticos y otros de baja o ninguna implicación cotidiana, lo que evidencia el distanciamiento de la vasta fauna y del imaginario amazónico. Cuando surgen las mascotas imaginativas, también las referencias son distantes, como la utilización de mitos romanos o de figuras universales, como el del genio. El mayor vínculo de sentido local está en la representación plural y extensiva de la Virgen de Nazaret como personaje, por lo tanto, mascota de las festividades del Círio. El presente artículo, a partir del proyecto de investigación titulado publiCIUDAD/ES que evalúa la propaganda y la publicidad como marca/s mediática/s de consumo, resultó en la presentación y publicación de cuatro trabajos en anales de eventos nacionales del área.

PALABRAS CLAVE Mascotas, Personajes, PubliCIUDAD, Consumo, Belém, Marca.

\section{PARA INÍCIO DE CONVERSA}

Desde que o mundo é mundo que os animais, seres reais ou imaginários, são parte importante nas lendas e nas mitologias clássicas (Minotauro, centauro, sereia, fênix, salamandra, Pégaso, ciclope etc.). Todos esses relatos, narrativas e discursos mitológicos são utilizados e reutilizados nos mais diversos campos do saber, como forma de contar e recontar histórias, e não podemos nos esquecer de que o discurso publicitário se apropria dos enunciados, conceitos e estratégias sobre os mitos e os utiliza para divulgar ideias e mensagens comerciais para o consumo de marcas, produtos e serviços.

Sob outra ótica, a mitologia apresenta-se como um discurso sobre os mitos, um saber que tenciona falar dos mitos em geral, de sua origem, de sua natureza, de sua essência; um saber com pretensões a se transformar em ciência, tanto hoje quanto outrora, pelos procedimentos usuais de estruturar alguns de seus objetos, sistematizar diferentes enunciados do saber que ela inaugura e formalizar conceitos e estratégias. (DETIENNE, 1998, p. 5)

Podemos modernamente aproximar o conceito de mito ao entendimento contemporâneo acerca das mascotes, já que o termo mascote é "um substantivo feminino atribuído a uma pessoa, animal ou objeto que se considera capaz de proporcionar sorte, felicidade, fortuna" (PEREZ, 2010, p. 41), e, mais ainda, são criaturas liminares, que oscilam entre o mundo material e a dimensão sobrenatural, entre o tangível e o etéreo, entre o real e o imaginário. "Representa um ponto de intersecção entre o humano e o divino. Sua ambiguidade constitutiva, como toda liminaridade, é performática, cênica e perturbadora” (PEREZ, 2010, p. 42). 
No mundo dos negócios da contemporaneidade, as mascotes estão presentes por toda parte, "notamos a presença de personagens e mascotes mais encarnadas, mais orgânicas em sua trajetória simbólica e vivência cotidiana”. (PEREZ, 2010, p. XVI), o que faz das mascotes, por trás de uma aparência nonsense, ser sacra e profana, real e irreal, numa profusão de pluralidade e significados, sendo, portanto, essencialmente ambígua.

Em um primeiro momento, pesquisamos os estabelecimentos comerciais localizados no comércio da cidade de Belém, relacionados com as mascotes animais gráficas, personagens que, segundo Perez (2010, p. 45), "são aquelas que representam as marcas, mas não manifestam fatos da vida, ou seja, são animais gráficos estáticos que funcionam como selo e, às vezes, como parte simbólica da identidade de marca”, ou ainda, que as mascotes animais não são representações ou animações de animais, e sim "os próprios animais expressos por meio de imagens fotográficas. 0 que está em causa aqui é a verossimilhança, é o real”. (PEREZ, 2010, p. 93). Assim, a primeira mascote assinalada é o canguru ${ }^{1}$, mascote comercial das lojas Radiolux (Figura 1), loja de departamentos fundada em 1951.

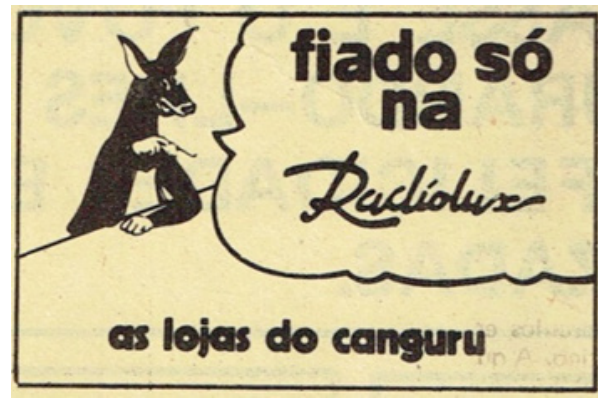

Figura 1. Canguru da Radiolux.

Fonte: Pará (1985). Jornal O Liberal, 1977.

A mascote da Superlojas era um Dinossauro ${ }^{2}$, também conhecida como "As lojas do Dino", e tinha como slogan "Ajudando você a viver melhor". O slogan sugere, com bom humor, que nas superlojas as condições de vida seriam muito melhores do que aquelas em que viveram os dinossauros que, como sabemos, desapareceram do planeta Terra.

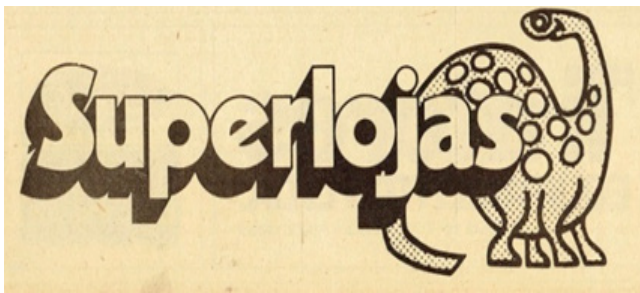

Figura 2. Dinossauro da Superlojas.

Fonte: Pará (1985). Jornal O Liberal, 1977.

1. Um mamífero marsupial que possui patas traseiras muito desenvolvidas, e a fêmea apresenta, na altura da barriga, uma bolsa (o marsúpio) na qual o filhote se desenvolve e pela qual é protegido até completar um ano de vida.

2. Em grego, "lagarto terrível". 
Em nossas pesquisas nos periódicos da publiCIDADE ${ }^{3}$ de Belém do Pará, encontramos diversos outros seres do mundo animal representando mascotes de marcas, mercadorias e serviços, tais como: caramujo, pinguim, cachorro, abelha, coruja, jacaré, urso polar, esquilo, leão, um peixe-boi (cientificamente denominado Manatus) e a tradicional casa de venda de carnes, também presente no mercado paraense, que apresenta imagens de boi, aves e suínos (Figura 3).

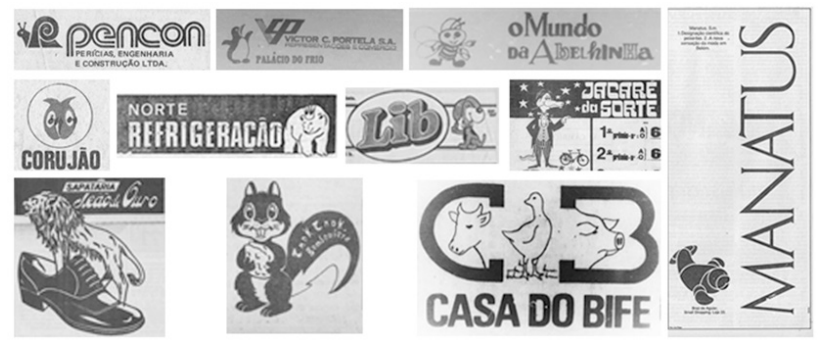

Figura 3. Mascotes animais.

Fonte: Pará (1985). Jornal O Liberal, 1972, 1976, 1977, 1979, 1980, 1987; jornal Folha do Norte, 1970.

Outro exemplo são os supermercados São João. Originalmente, a personagem utilizada como mascote era o santo que dá nome ao empreendimento, o qual aparecia com uma ovelhinha nos braços. Contudo, com os anos, passou-se a utilizar uma imagem do santo com características infantis e, posteriormente, somente a representação da ovelha (Figura 4). $\mathrm{O}$ animal ganhou maior destaque na marca, talvez em função de amenizar a utilização diária da imagem religiosa do santo e, assim, tornar mais palatável massificar diariamente a imagem de um animal dócil e com representação tão positiva como a ovelha.

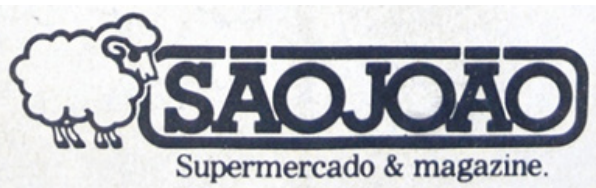

Figura 4. Mascote - ovelha dos supermercados São João.

Fonte: Pará (1985). Jornal O Liberal, 1983.

Ainda em nossas pesquisas nos periódicos da publiCIDADE de Belém do Pará, outros seres do mundo animal são identificados como representantes das mascotes de marcas, a saber: pinto, coelho, frango e gato (Figura 5).

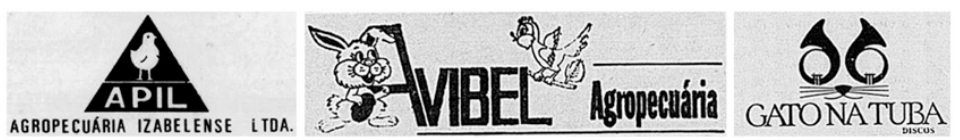

Figura 5. Mascotes - pinto, coelho, frango e gato.

Fonte: Pará (1985). Jornal Diário do Pará, 1984; jornal O Liberal, 1989.

3. Termo grafado de modo a criar um trocadilho entre a palavra "publicidade" e o nome do nosso projeto de pesquisa, "PubliCIDADE", o qual analisa a propaganda publicitária como marca midiática de consumo. 
Canevacci (2001, p. 15) afirma que "o fetichismo visual 'vê' as novas mercadorias sempre mais como sujeitos, com biografia própria, biologia e vida social”. Podemos então considerar as mascotes como um dos símbolos, um dos sinais desse "corpo" que tem vida, com seus fetiches mercadológicos e biografias, nas quais a leitura das mascotes encontramos todas as suas dimensões visuais que emanam tanto das suas formas gráfico-visuais (desenho, cores, formas etc.), quanto das culturais e estéticas (mensagens e signos) e comunicacionais (publicidade e propaganda). Assim, partindo desta inicial análise, é importante frisar que a maioria das mascotes animais são aves, répteis e mamíferos e, apesar da enorme e rica fauna, tanto real quanto lendária, existente na floresta amazônica, são pouquíssimos os usos dessa variedade de animais como símbolos e imagens comerciais das empresas nascidas e criadas no mercado paraense.

\section{MASCOTES IMAGINÁRIAS}

Desde os tempos mais remotos, a questão da existência ou não de seres imaginários perpassa as histórias, mitos, contos e lendas, o que nos remete às mascotes, seres que por trás de uma provável aparência nonsense, sacra e profana, real e irreal, mas que sempre integra uma profusão de significados. As mascotes são essencialmente ambíguas, como podemos observar:

Os mitos são muitas vezes manifestações por meio de relatos fantásticos de tradição oral geralmente protagonizados por seres que encarnam, de forma simbólica, as forças da natureza e os aspectos gerais da condição humana e, por isso, são fortemente associados às lendas e às fábulas. (PEREZ: 2010, p. 55)

Perez (2010, p. 41) afirma que o termo "mascote” é atribuído a uma pessoa, animal ou objeto considerado capaz de proporcionar sorte, felicidade, fortuna. "É uma criatura liminar, que oscila entre o mundo material e a dimensão sobrenatural, entre o tangível e o etéreo, entre o real e o imaginário. Representa um ponto de intersecção entre o humano e o divino”. Na contemporaneidade, as mascotes ganham maior presença e realce no mundo dos negócios e das marcas (produtos e serviços), já que, segundo Perez (2010, p. XVI), "tinham o papel inequívoco de aproximar produto/marca dos consumidores, sendo, em muitos casos, portadores de didatismo necessário aos pioneiros em novos mercados”. As mascotes são utilizadas na comunicação publicitária, muitas vezes, como representações novas de personagens mitológicos antigos, usados indiscriminadamente para anunciar e vender os mais diversos produtos e serviços, dos mais variados gêneros mercadológicos.

Em nossas pesquisas nos jornais da publiCIDADE de Belém do Pará, encontramos diversos seres mitológicos utilizados como mascotes de marcas, mercadorias e serviços, tais como: dragão, escorpião, cegonha, fênix, centauro e a tradicional imagem da loba amamentando os gêmeos Rômulo e Remo (Loba Capitolina), para vender leite (Figura 6). 

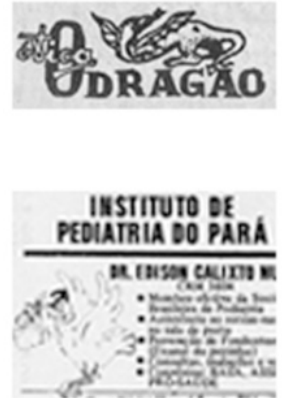
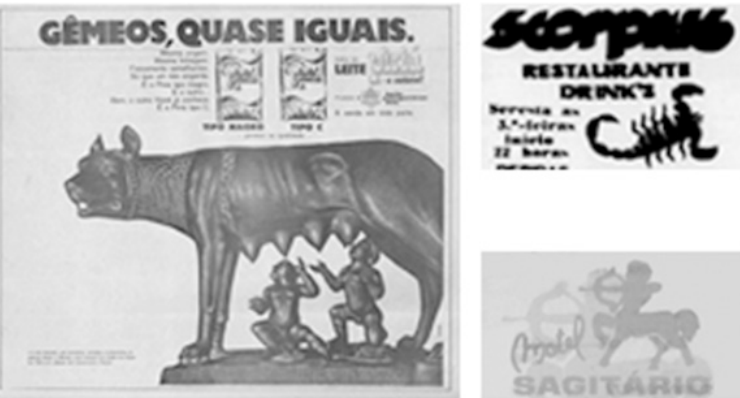

Figura 6. Mascotes - dragão, escorpião, cegonha, fênix, centauro e a Loba Capitolina. Fonte: Pará (1985). Jornal O Liberal, 1972, 1977, 1989 e 1999, jornal Diário do Pará, 1982.

A publicidade mítica seria como uma máquina produtora de mundos imagináveis, portadoras de felicidade, fazendo das coisas (objeto e marcas) normais algo diferente. Um comerciante de sapatos, segundo essa ideologia, não vende sapatos, mas belos pés. “O negócio da publicidade é de dar talento ao consumo. Ela deve apagar o monótono da compra cotidiana, revestindo de sonho os produtos que, sem ela, seriam apenas o que realmente são" (SÉGUÉLA apud GARBOGGINI, 2003, p. 48). Outras personagens lendárias também encontradas no mercado paraense foram: o anjo, o gênio da lâmpada, o semideus Hércules, o índio Tupã e o "bom velhinho" Papai Noel (Figura 7).
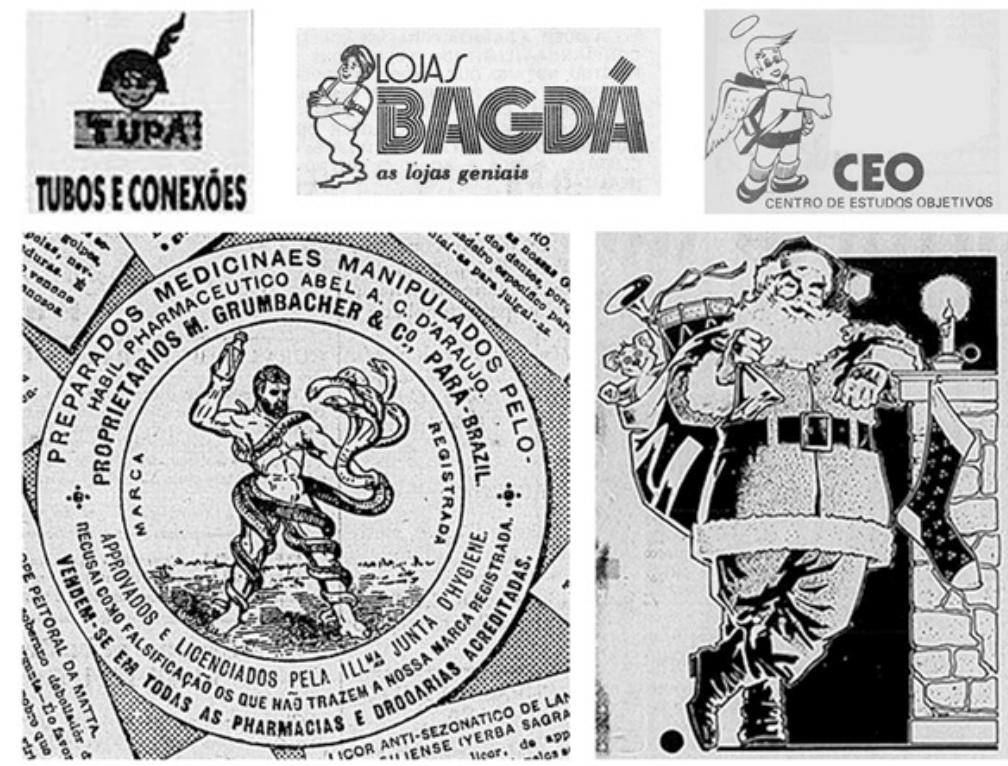

Figura 7. Mascotes imaginárias.

Fonte: Pará (1985). Jornal O Liberal, 1951, 1976, 1977, 1987, jornal Folha do Norte, 1896.

Também encontramos as mascotes tecnológicas que se utilizam de seres e objetos modernos, como a lâmpada com corpo humano representando um mexicano da Pepi Luminotécnica, a lâmpada com corpo humano de A Iluminadora e o Robô da Setec (Figura 8). Esses são casos típicos de antropomorfizações de produtos e marcas, como observado na classificação das mascotes de Perez (2010). 

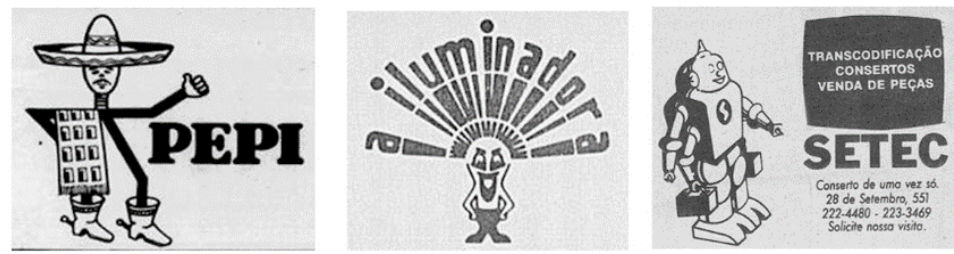

Figura 8. Mascotes tecnológicas.

Fonte: Pará (1985). Jornal Diário do Pará, 1984; jornal O Liberal, 1987, 1989.

As mascotes, personagens e personalidades, por meio da comunicação publicitária, contribuem midiaticamente para a propagação e a massificação das lendas e mitologias, suscitando a imaginação e favorecendo o consumo:

O sentido está na fantasia individual ou no imaginário coletivo projetado sobre o mundo, informando-lhe e dando-lhe significado. $\mathrm{O}$ produto será investido de valor pela história imaginária apresentada pela narrativa. Para tanto, utiliza recursos como as lendas, os heróis, os símbolos - papéis temáticos já fortemente estruturados, extremamente conhecidos e que servem de estrutura de recepção do produto, como o cowboy de Marlboro. (GARBOGGINI, 2003, p. 48)

Em nossas pesquisas, realizadas nos periódicos da publiCIDADE de Belém do Pará, podemos ainda identificar outras representações de seres humanos como mascotes de marcas no mercado (Figura 9), mas continuamente representados de forma simplificada, com poucos traços e sem investimentos em fatos de vida.

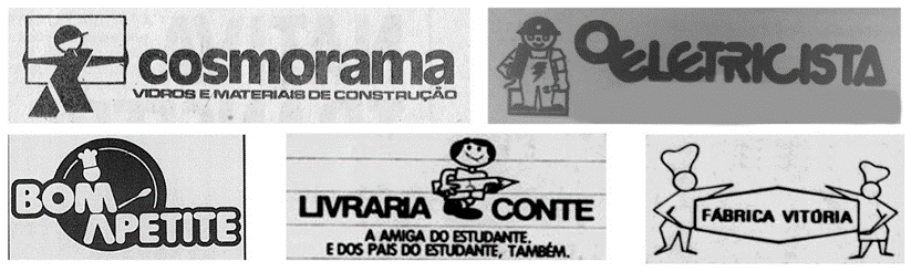

Figura 9. Mascotes humanas.

Fonte: Pará (1985). Jornal O Liberal, 1977, 1981, 1989; jornal Diário do Pará, 1984.

Quando tomamos o vocábulo perssonage, entendemos que sua construção é decorrente da junção de "pessoa" + "age” - pessoa em ação, daí o vínculo com o movimento da face, rosto, semblante e também máscara, como simulacros de expressão e movimentos (PEREZ, 2010, p. 1). Ainda, para Perez (2010, p. XV), "a publicidade incrementa e diversifica seu poder e converte-se em uma poderosa ferramenta, muito valiosa para transmitir e demonstrar os atributos dos produtos e os valores simbólicos das marcas e das corporações”, e esses valores simbólicos também perpassam pelo religioso, pois, ao olharmos a imagem simbólica de um santo - como o caso do já citado supermercado São João -, ou a imagem de uma santa - como a padroeira dos paraenses, Nossa Senhora de Nazaré -, como personas comerciais, podemos imaginar Nossa Senhora de Nazaré, a principal "persona" do Círio, como a "mascote" representativa de toda a publiCIDADE das festividades do Círio e a marca simbólica mais forte da quadra nazarena (Figura 10). 


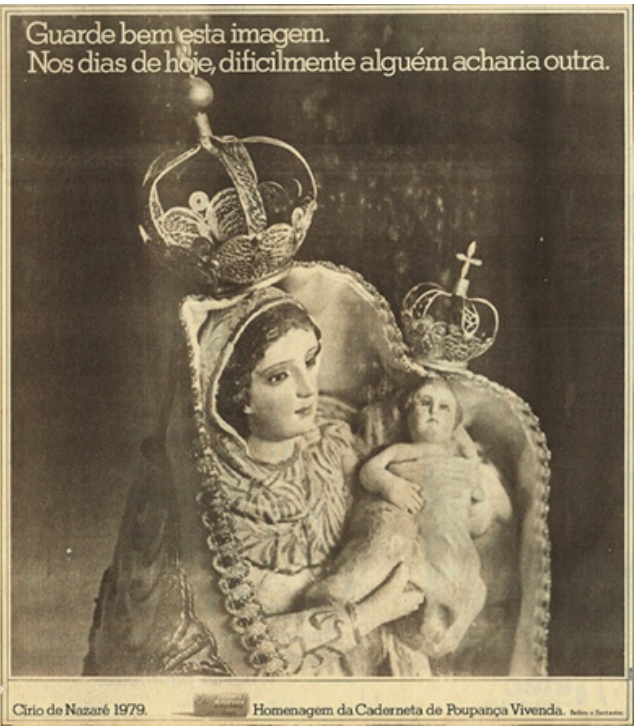

Figura 10. Anúncio Vivenda - Nossa Senhora de Nazaré.

Fonte: Pará (1985). Jornal O Liberal, 1979.

Historicamente, o mito fundador do Círio de Nazaré conta que o caboclo Plácido José de Souza, em 1700, encontrou uma imagem da Virgem de Nazaré às margens do Igarapé Murutucu. Plácido levou a imagem para sua cabana, porém, no dia seguinte, ela havia desaparecido. Ao voltar para o lugar da aparição, ele a encontrou novamente. A história se repetiu por várias vezes até que a imagem foi trancafiada no Palácio do Governo, mas sumiu, e no dia seguinte foi encontrada no lugar da sua primeira aparição. Em virtude disso, o governador da época mandou erguer uma ermida no local do achado, onde atualmente está localizada a Basílica Santuário de Nossa Senhora de Nazaré. O "achado" da imagem da santa é contado, recontado e ilustrado em diversos anúncios comemorativos do Círio de Nazaré, assim como a imagem de Nossa Senhora é utilizada nos anúncios publicitários de diferentes formas icônicas, da ilustração à fotografia.

As personagens de marca surgem quando a vinculação é mais profunda, ou seja, quando a personagem é um sinal distintivo e diferenciador, de uso exclusivo da marca, e acaba por se tornar um elemento de sua identidade. (PEREZ, 2010, p. 39)

Não é à toa que desde os primórdios do Círio os "patrocinadores da fé", empresas, lojas e marcas de alimentos, refrigerantes, cervejas, cigarros, vestuário, tecidos, e construtoras, bancos, agências de publicidade e os governos federal, estadual e municipal se fazem presentes em diversos anúncios publicitários nos jornais paraenses, com o intuito de homenagear a Santa e o Círio de Nazaré e, mais ainda, durante todo o período das festividades do Círio encontramos a imagem personalizada de Nossa Senhora de Nazaré representada nas diversas estampas nas camisetas, fitinhas, bandeirolas, chaveiros, botons, miniaturas da Santa, além dos cartazes de divulgação do Círio, elementos religiosos/mercadológicos (souvenires) que compõem todo um material publicitário, incluindo também os anúncios publicados nos jornais e revistas locais e os outdoors espalhados pelas ruas e avenidas da cidade, que formam um mosaico da Santa, a persona principal do Círio de Nazaré. 


\section{PUBLICIDADE, MASCOTES E A CONSTRUÇÃO DAS MARCAS}

A publicidade, desde seu surgimento como atividade econômica, se utiliza de vários recursos estratégicos, imaginativos e estéticos, como seres e representações mitológicas, animais, antropomorfizações e tantos outros recursos, sempre com o objetivo de construir sentidos positivos para as ofertas. Com esse intuito, a comunicação publicitária se utiliza das mascotes como representações mercadológicas dos produtos e serviços anunciados nos meios de comunicação e, assim, reafirma a identidade do consumidor, que aparece representado nas mensagens publicitárias, utilizando o produto ou o serviço anunciado, tendo por premissa o significado principal de marca que, segundo Batey (2010, p. 210), “é o resumo das principais associações feitas pelo consumidor e das percepções dominantes sobre ela, uma fotografia instantânea que imediatamente vem à mente ao se ouvir o nome da marca". Simplesmente, para o autor, "é a maneira pela qual o consumidor define certa marca espontaneamente". Assim, o estudo e a análise das peças publicitárias apresentadas neste artigo têm como foco o registro histórico das representações imagéticas das mascotes utilizadas pelas empresas comerciais na cidade de Belém do Pará, bem como a compreensão das estratégias recorrentes na construção das mascotes de marcas.

Para Batey (2010, p. 27), “um produto físico se torna uma marca quando é acrescido de algo mais - imagens, símbolos, percepções, sentimentos para produzir uma ideia total maior do que a soma de suas partes”. Daí a importância de estudarmos as mascotes como forma de publicização de marcas por meio da construção de vínculos de sentido (PEREZ, 2017) entre consumidores, produtos e serviços no contexto paraense.

De modo geral, concomitantemente ao aparecimento e desenvolvimento do comércio, surgem também as formas de divulgação, entrando em cena a atividade da publicidade e da propaganda. A história das atitudes em relação ao objeto e à mercadoria em nossa sociedade é aqui capital - ela postula que uma história do consumo é uma maneira de reconciliar o sujeito com o objeto, a interioridade com a exterioridade. O principal argumento da história da civilização material é a relação dos homens com as coisas e os objetos (ROCHE, 2000, p. 17). Portanto, o mundo moderno, bem como o pós-moderno e, consequentemente, o mundo contemporâneo são considerados “mundos” permeados constantemente pelas imagens e, junto com elas, apresentam-se também a imaginação, a fantasia, os mitos e as lendas que, segundo Durand (2002, p. 18), compõem "o conjunto das imagens e relações de imagens que constitui o capital pensado do homo sapiens". Entenderemos por mito um sistema dinâmico de símbolos, arquétipos e esquemas - sistema dinâmico que, sob o impulso de um esquema, tende a compor-se em narrativa. O mito é um esboço de racionalização, dado que utiliza o fio do discurso, no qual os símbolos se resolvem em palavras e os arquétipos, em ideias. (DURAND, 2002, p. 62-63). Nesse sentido, a publicidade faz uso de vários recursos para a otimização dos efeitos de sentido que pretende, como podemos observar nas palavras de Soulages (1996, p. 151):

A publicidade coloca em cena e reconstitui universos de referência. Estes podem ficar circunscritos no espaço (a cidade, a natureza, lugares conhecidos etc.), corresponder a práticas sociais (trabalho, lazer...), familiares, individuais, comportamentais (sedução...). Eles podem igualmente estar implícitos em espaços míticos preexistentes (religião, romances, filmes etc.), ou simbológicos (o exotismo, a pureza, a 
aventura etc.), ou, mais raramente, estar incorporados ao próprio produto, como é o caso do automóvel, saturado, em nossas sociedades, de investimentos simbólicos maciços.

\section{CONSIDERAÇÕES FINAIS}

A pesquisa realizada nos jornais impressos paraenses e na Junta Comercial do Estado do Pará (Jucepa), para a produção da presente pesquisa, teve como objetivo a compilação de um inventário imagético das mascotes publicitárias utilizadas pelas empresas comerciais na cidade de Belém do Pará, com vistas ao entendimento das principais estratégias empregadas em suas construções. Desse modo, a pesquisa realizada sobre as mascotes, personagens e personalidades do imaginário amazônico utilizadas no mercado paraense para a construção e sustentação de marcas nos remetem ao fato de que todos esses relatos, narrativas e discursos sobre mitos, personagens e animais são sempre utilizados e reutilizados nos mais diversos segmentos da vida material, como forma de contar e recontar histórias das mais diversas e facilitar os vínculos de sentido e, quiçá, de consumo. Porém, com relação à mitologia das mascotes imaginárias encontradas no mercado paraense, vale ressaltar a pouca ênfase e utilização de seres e animais mitológicos e lendários da própria região amazônica pelas empresas paraenses em sua comunicação publicitária, o que nos leva ao entendimento de que as opções empregadas seguem por caminhos mais previsíveis, como por exemplo, na utilização de animais domésticos (gato e cachorro) ou de agradável convívio, como é o caso da ovelha, do coelho, do canguru, ainda que totalmente distantes da realidade local. Outro fenômeno é a escassez de aves ou de mitologias locais, como o boto ou o saci como mascotes de marcas locais, o que reforça a perspectiva do distanciamento do imaginário lendário amazônico. Mesmo quando fazem uso de mascotes imaginativas, as marcas optam por mitologias mundiais, ainda que distantes, já consagradas, como é o caso da Loba Capitolina para comunicar uma marca de leite local. Também foram encontradas utilizações de antropomorfizações de produtos e objetos por meio de recursos de simplificação, o que revela o pouco investimento criativo e comunicacional nessa estratégia de comunicação marcária.

No entanto, a expressão mais identitária da região está na utilização da imagem da Nossa Senhora de Nazaré em toda a comunicação publicitária das festividades do Círio. A Santa torna-se personagem, portanto, umas das possibilidades de construção de mascotes, de todas as festividades do Círio, sendo sistematicamente apropriada em suas representações verossímeis, estilizadas ou mesmo simplificadas. Aqui encontramos forte vínculo local na publicidade, por meio da utilização de uma personagem que é a padroeira da cidade e que conta com a reiteração dos vínculos construídos há séculos pelas narrativas religiosas da Santa.

\section{REFERÊNCIAS}

BATEY, M. O significado da marca: como as marcas ganham vida na mente dos consumidores. Rio de Janeiro: Best Business, 2010.

CANEVACCI, M. Antropologia da comunicação visual. Rio de Janeiro: DP\&A, 2001.

DETIENNE, M. A invenção da mitologia. Rio de Janeiro: José Olympio/Edunb, 1998. 
GARBOGGINI, F. B. A semiótica como instrumento de análise da publicidade. Comunicarte, Campinas, v. 21, n. 27, p. 37-52, 2003.

PARÁ. Secretaria de Cultura do Estado. Jornais Paroaras: catálogo. Belém do Pará: Secdet, 1985.

PEREZ, C. Mascotes: semiótica da vida imaginária. São Paulo: Cengage Learning, 2010 Signos da marca: expressividade e sensorialidade. 2. ed. São Paulo: Cengage, 2017.

ROCHE, D. História das coisas banais: nascimento do consumo nas sociedades dos séculos XVII ao XIX. Rio de Janeiro: Rocco, 2000.

SOULAGES, J-C. Discurso e mensagens publicitárias. In: CARNEIRO, A. D. (org.). O discurso da mídia. Rio de janeiro: Oficina do Autor, 1996. p. 142-154. 